\title{
Influence of canopy development in the vineyard on spray deposition from a tunnel sprayer
}

\author{
Gianfranco Pergher, Nicola Zucchiatti \\ Department of Agricultural, Food, Environmental and Animal Sciences, University of Udine, Italy
}

\begin{abstract}
Spray deposition from a tunnel, air-assisted sprayer was analysed during the whole season, following canopy development in a vertical-shoot-positioned vineyard. Four field tests were performed using hollow-cone, turbulence nozzles between the $\mathrm{BBCH}$ 15 (5 leaves unfolded) and BBCH 77 (berries beginning to touch) growth stages, plus an additional test with flat-fan, air-injection nozzles at BBCH 77. The main canopy parameters were assessed, including the canopy height range $(0.6 \mathrm{~m}$ to $1.4 \mathrm{~m})$, the leaf area index $(L A I ; 0.15$ to 1.60$)$ and the leaf layer index $(L L I ; 0.69$ to 2.74). Total deposition on target (leaves and bunches) increased from $14.8 \%$ to $53.9 \%$ of volume applied, and was significantly related to the $L L I\left(\mathrm{R}^{2}=0.943\right)$; the relevance of such relationship in connection with the leaf wall area model for volume rate adjustment is discussed in the paper. Losses to the ground (1.9\% to $8.1 \%$ of volume applied), spray recovery rate $(31.0 \%$ to $67.2 \%)$ and losses owing to evaporation of the recycled liquid $(0.1 \%$ to $3.5 \%)$ were also analysed. At BBCH 77, air-injection nozzles did not improve overall deposition in comparison to hollow-cone nozzles, but increased spray recovery (from $31.0 \%$ to $36.1 \%$ ) and reduced (to $0.1 \%$ ) evaporation of the recycled liquid, so that they may represent an option to avoid an excessive concentration in the tank towards the end of application.
\end{abstract}

\section{Introduction}

Tunnel, recycling sprayers for orchards and vineyards have been proposed since the late ' 80 (Bera, 1985; Siegfried and

\footnotetext{
Correspondence: Gianfranco Pergher, Department of Agricultural, Food, Environmental and Animal Sciences, University of Udine, via delle Scienze 206, 33100 Udine, Italy.

E-mail: gianfranco.pergher@uniud.it

Key words: Recycling sprayer; leaf layer index; leaf area index; mass balance; leaf wall area model.

Received for publication: 19 October 2017.

Accepted for publication: 28 January 2018.

(C) Copyright G. Pergher and N. Zucchiatti, 2018

Licensee PAGEPress, Italy

Journal of Agricultural Engineering 2018; XLIX:801

doi:10.4081/jae.2018.801

This article is distributed under the terms of the Creative Commons Attribution Noncommercial License (by-nc 4.0) which permits any noncommercial use, distribution, and reproduction in any medium, provided the original author(s) and source are credited.
}

Raisigl, 1991; Baraldi et al., 1993) in order to improve spray deposition efficiency and reduce drift losses to the environment. Only recently, however, they are increasingly replacing conventional, broadcast sprayers in the field practice, particularly in vineyards located in flatlands, owing to the introduction of improved, air-assisted models (Ade et al., 2007; Baldoin et al., 2008; Pergher and Petris, 2009; Tamagnone et al., 2013) and to the impulse of Directive 2009/128 (European Union, 2009) towards a more sustainable use of pesticides.

Tunnel sprayers are fitted with shields, designed to enclose the canopy, contain drift, and recover the excess spray not retained by the foliage; a recycling circuit connects the basins placed at each shield's bottom with the sprayer's tank so as to recycle the recovered liquid. They can be divided in several categories. Tunnel sprayers without any air-assistance may be simpler in construction and less expensive; however, uneven deposition over the foliage has been reported (Siegfried and Holliger, 1996), also associated with poor pest control in comparison to conventional sprayers (Viret et al., 2003). Air-assisted tunnels with external air intake (Planas et al., 2002) must discharge to the outside the air volume fed by the fans into the tunnel, with the risk of losing some fraction of the smaller droplets and so increasing drift. Therefore, models with internal tangential-flow fans (Siegfried and Holliger, 1996) or axial-flow fans (Molari et al., 2005) have been proposed, working on the closed-loop concept of re-circulating the same volume of air inside the tunnel. The problem of fan contamination may be reduced by lamellae separators at the fan's intake (Ade et al., 2007). An alternative solution may be to combine external fans with separator screens integrated in the shields, so as to filter and capture the liquid not retained by the canopy, while discharging the air to the outside (Panneton et al., 2005; Pergher and Petris, 2009; Ambrogetti et al., 2016). This avoids most of the above problems, while posing lesser constraints as to the size and air flow rate of the fans; additionally, the width and weight of the shields can be reduced, thus allowing quicker and more efficient folding-up of the tunnel structure, particularly during turning operations, as required to improve manoeuvrability and safety particularly in narrow-spaced vineyards.

Field tests performed with a vineyard tunnel sprayer, fitted with lamellate separating panels (Pergher and Petris, 2009), showed that the recovery rate ranged from $77 \%$ to $34 \%$ of the spray volume, depending on the growth stage (i.e., decreasing from bud break to full foliage development, respectively). A further comparison with a conventional, broadcast sprayer resulted in comparable mean foliar deposition at end of flowering and beginning of ripening (Pergher et al., 2013). However, the tunnel sprayer gave increased deposit variability on leaf undersides at the end of flowering, possibly owing to incorrect angling of airflows towards the canopy. In general, these tests pointed on the importance of correctly adjusting the sprayer's settings at each different growth stage of the vines, particularly the tunnel opening (i.e., the horizontal distance between the shields) and the angling of air 
flows, in order to contain the spray cloud in the inside of the tunnel, reduce drift losses and improve deposition to the canopy.

Based on these results, it seemed important to further analyse the tunnel sprayer's deposition efficiency and recovery rate over a wider range of growth stages of the vines, and to relate them to the crop parameters, such as canopy size and foliar density, so as to contribute to a better understanding of the relationship between morphological parameters of vine canopies and spray deposition. Further objectives of the present study were: to assess spray losses owing to spray deposition to the ground, and to partial evaporation of the recovered liquid, that might also cause an undesired increase in pesticide concentration; and to compare hollow-cone nozzles with flat-fan, air injection nozzles in terms of spray deposition, spray recovery rate and concentration rise in the recycled liquid.

\section{Materials and methods}

Five field tests were performed at four different growth stages of the vines (Table 1): i) 5 leaves unfolded, BBCH 15 (Lorenz et al., 1994); ii) inflorescences fully developed, $\mathrm{BBCH} 57$; iii) berries groat-sized, $\mathrm{BBCH} 73$; iv) berries beginning to touch, $\mathrm{BBCH} 77$ (two tests).

Test 1 was conducted in Romans d'Isonzo (Gorizia, Italy). The vineyard was trained to a guyot (cv: Pinot Grigio), with the renewable cordon at $0.9 \mathrm{~m}$ height from the ground; planting distances were $2.7 \mathrm{~m}$ between the rows, and $0.8 \mathrm{~m}$ between the vines. Tests 2 to 5 were performed in San Martino al Tagliamento (Pordenone, Italy), in different parts of the same vineyard (total area: 2.71 ha; $\mathrm{cv}$ : Merlot). The vines were trained to a horizontal spur-cordon, at $0.8 \mathrm{~m}$ height from the ground; planting distances were $2.4 \mathrm{~m}$ between the rows, and $0.8 \mathrm{~m}$ between the vines. In both vineyards, canopy management operations were performed during the season, including: suckering (i.e. the removal of shoots arising from below the cordon), side and top trimming, vertical shoot positioning (VSP) (by manually lifting of moveable catch wires; before $\mathrm{BBCH}$ 57, i.e. before Test 2), and cluster thinning (after $\mathrm{BBCH} 73$, i.e. before tests 4 and 5). Additionally, partial leaf removal in the fruit zone was performed after $\mathrm{BBCH} 77$, and did so not affect the spray tests.

The sprayer (Figure 1) was a two-row, trailed, recycling tunnel sprayer (Model: Drift Recovery, Agricolmeccanica s.r.l., Torviscosa, Udine, Italy). Each of the two tunnel units consisted of a couple of symmetrical shields, each (Figure 2): an axial-flow fan; a vertical air duct, fitted with six air outlets, spaced at $220 \mathrm{~mm}$ intervals; a vertical boom with six hydraulic nozzles; an air/droplet separator panel with vertical lamellae; and a recovery basin connected with the recycling circuit. The distances between the tunnel units, and between the shields in each unit, could be adjusted by means of hydraulic actuators to fit the row spacing of the crop (between $1.8 \mathrm{~m}$ to $3.6 \mathrm{~m}$ ), and the width of the vine canopy (between $0.5 \mathrm{~m}$ and 1.0). Both the main air duct and the air outlets could be rotated in the horizontal or vertical plane, respectively, to adjust the directions of the outcoming airflows, relative to the canopy and/or the separator panel. The sprayer was fitted with two diaphragm pumps: the main pump, connecting the tank to the nozzles; and the recycling pump, connecting the recovery basins with the tank.

During the field tests, the angling of the air ducts and nozzles, $(\alpha)$ in Figure 2, was adjusted at $0^{\circ}$ (front booms) and $30^{\circ}$ (rear booms); i.e., the air outlets and nozzles were directed at $90^{\circ}$ relative to the row direction (front booms), or rotated by $30^{\circ}$, towards the inside of the tunnel (rear booms). This was meant to compensate for the effect of the external volume of air, entering the tunnel from the front opening at a relative speed equal to the travel speed, as suggested by previous studies (Pergher and Petris, 2009; Pergher et al., 2013). The tunnel opening, i.e. the horizontal dis-

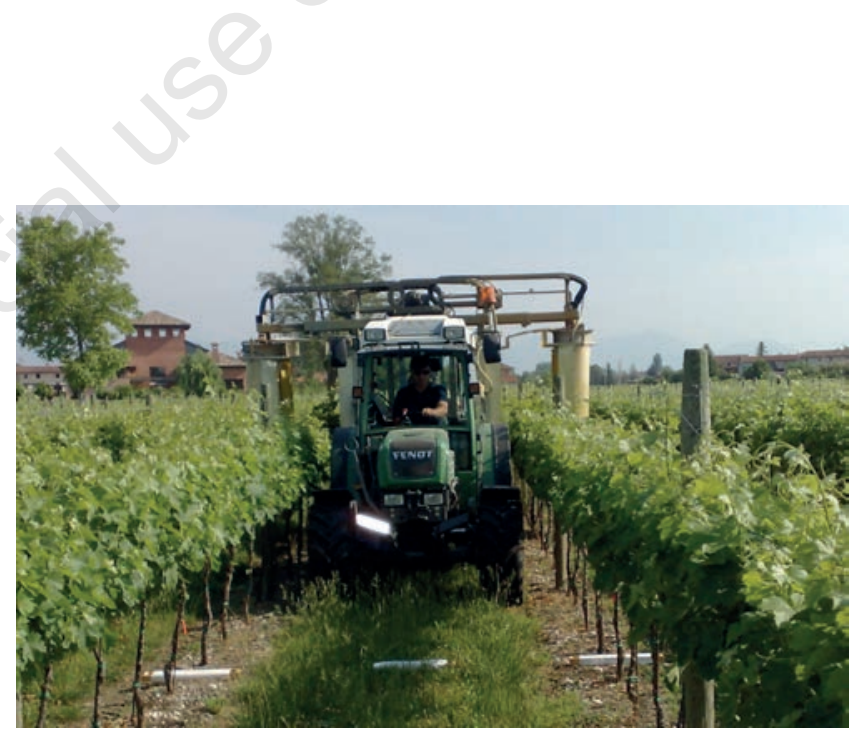

Figure 1. The tunnel sprayer during Test 2.

Table 1. The field tests and the sprayer settings.

\begin{tabular}{|c|c|c|c|c|c|}
\hline Test & 1 & 2 & 3 & 4 & 5 \\
\hline Training system & Guyot & Spur cordon & Spur cordon & Spur cordon & Spur cordon \\
\hline Date & May 8 & May 21 & June 16 & July 8 & July 8 \\
\hline Growth stage & BBCH 15 & BBCH 57 & BBCH 73 & BBCH 77 & BBCH 77 \\
\hline Row distance, $\mathrm{m}$ & 2.7 & 2.4 & 2.4 & 2.4 & 2.4 \\
\hline Nozzle type & Abbà green & Abbà green & Abbà green & Abbà green & AVI yellow \\
\hline Open nozzles per side & 3 & 4 & 6 & 6 & 6 \\
\hline Pressure, MPa & 0.60 & 1.00 & 1.00 & 1.00 & 0.57 \\
\hline Output per nozzle, L/min & 0.84 & 1.09 & 1.11 & 1.11 & 1.11 \\
\hline Forward speed, m/s & 2.08 & 2.11 & 2.11 & 2.11 & 2.11 \\
\hline Application volume rate, L/ha & 150 & 287 & 440 & 440 & 440 \\
\hline Tunnel opening, mm & 800 & 550 & 600 & 650 & 650 \\
\hline
\end{tabular}


tance between the shields, (g) in Figure 2 was adjusted at $800 \mathrm{~mm}$ in Test 1 (Table 1) to avoid touching and possibly damaging the foliage; in fact, vertical shoot positioning had not yet been performed, and some of shoots were protruding from the row line. In Tests 2 to 5 , however, tunnel opening could be reduced at 550 to $650 \mathrm{~mm}$ (Table 1) so as to match the canopy width as close as possible. The fans were adjusted to give an airflow rate of $2.23 \mathrm{~m}^{3} / \mathrm{s}$ per row, i.e. the total output of two fans (Pergher and Petris, 2009; Pergher et al., 2013).

The number of open nozzles was chosen so as to match the canopy size at each growth stage, following visual assessment. The nozzles and air outlets were first directed horizontally towards the canopy; then, the inclination of the top and bottom ones was adjusted (i.e., rotated in the vertical plane) to fit the actual canopy height range at each growth stage. This resulted in 3 to 6 open nozzles per side of the row (Table 1). In Tests 2 to 4, Abbà 1035.015 (green), hollow-cone nozzles were used, giving (at $1 \mathrm{MPa}$ ) a very fine droplet distribution, according to BCPC classification (Southcombe et al., 1997) and based on Manufacturer's information (Abbà s.n.c., www.abbadiserbo.it). The same was done in Test 1 , but pressure was reduced to $0.6 \mathrm{MPa}$, in an attempt to produce a coarser distribution and so reduce drift losses from the back tunnel opening. In Test 5, Albuz AVI 80.02, flat-fan, air-injection nozzles were used to produce a coarse BCPC distribution (Albuz, www.albuz.com). The nozzle output was checked, prior to each test, using graduated cylinders connected to the nozzles by flexible pipes; the resulting spray volumes, at $2.08-2.11 \mathrm{~m} / \mathrm{s}$ forward speed, were 150 to $440 \mathrm{~L} /$ ha (Table 1 ).

Despite the differences in the sprayer's settings and the vineyard between Test 1 and Tests 2 to 5 , it seemed interesting to include the former in the present study as well. The effects of such differences shall be analysed in the Results section.

At each growth stage, the spray area included six rows of the vineyard, i.e. three complete passes of the sprayer over a length of $281 \mathrm{~m}$ (Tests 2 to 5 ) or $250 \mathrm{~m}$ (Test 1). Prior to spraying, two sample vines were selected for deposit assessment in the two middle rows, corresponding to the central pass of the sprayer, with four replicates (Tests 1-3) or three replicates (Tests 4-5) spaced at least $30 \mathrm{~m}$ along the rows. Wooden frames $(500 \mathrm{~mm} \times 100 \mathrm{~mm})$, covered with absorbent paper (Scottex ${ }^{\circledR}$ white), were used to collect the deposits on the ground, and placed at five locations across the two central rows, i.e. under the left-hand ( $\mathrm{LH})$ and right-hand (RH) rows, relative to the sprayer; under the next row to the right; and in the middle of the lanes between the rows (Figure 3).

Before spraying, 30 untreated leaves were taken for the assessment of background deposits and placed each in a Petri dish. The spray mixture contained 5.1 to $5.7 \mathrm{~g} / \mathrm{L}$ of a water-soluble food dye used as a tracer (Tartrazine, Novema s.r.l.), and 2.3 to $2.6 \mathrm{~g} / \mathrm{L}$ of a
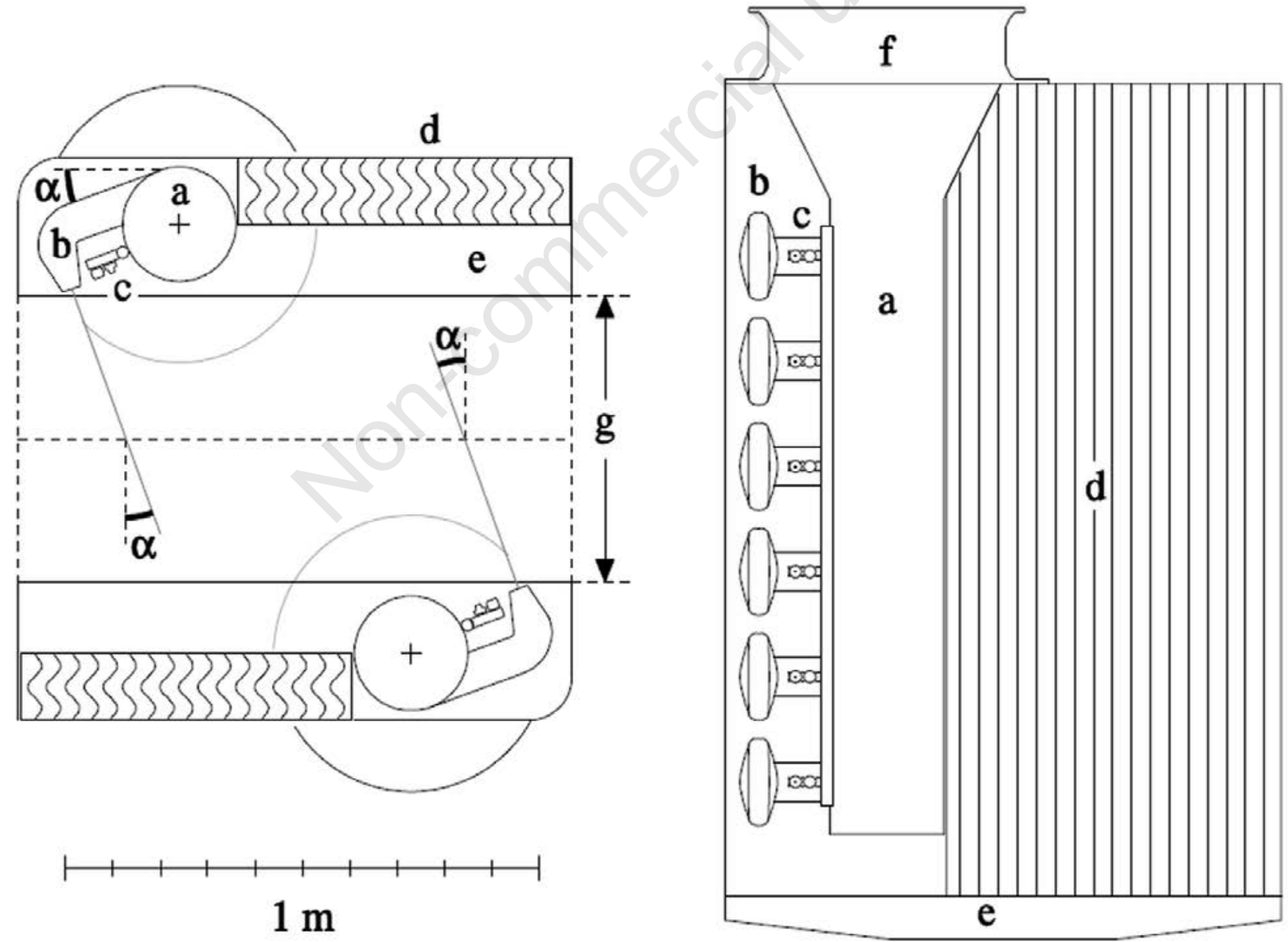

Figure 2. Schematic views of the tunnel sprayer (left tunnel unit). Left: from the top; right: from the (inner) side. (a) main air duct; (b) air outlets; (c) nozzles; (d) air/droplet separator; (e) basin; (f) fan; (g) tunnel opening; ( $\alpha$ ) air jet inclination. 
pesticide (Penncozeb 20, Cerexagri), added to retain the physical properties of a standard spray mixture, particularly because of the surfactants contained as additives. All tests were performed between 9:00 $\mathrm{h}$ and 11:30 $\mathrm{h}$ in the morning, with similar weather conditions. Air temperature was $21.3^{\circ} \mathrm{C}$ to $24.0^{\circ} \mathrm{C}$, with $50 \%$ to $67 \%$ relative humidity, and the mean wind speed was 1.0 to $1.8 \mathrm{~m} / \mathrm{s}$ during spray application.

During the central pass of the sprayer, i.e. spray application on the two middle rows, the connection pipe between the recycling pump and the tank was deviated in a separate container (capacity: $20 \mathrm{dm}^{3}$ ), in order to collect the liquid recovered by the lamellae separators. Samples of the spray mixture $(200 \mathrm{~mL})$ were taken from the nozzles at the beginning and at the end of the central spray pass.

After spraying, all wooden frames were collected, and a portion of paper $(80 \times 465 \mathrm{~mm})$ was cut out and stored in a container for deposit assessment. In Tests 1 and 2, twelve leaves were randomly collected from the sample vines for deposit assessment. In Tests 3 to 5, two leaves were collected from each of nine locations in the canopy of each sample vine (Figure 3), resulting from:

- three height ranges: i) from $0.7 \mathrm{~m}$ to $1.15 \mathrm{~m}$ from the ground; ii) $1.15 \mathrm{~m}$ to $1.6 \mathrm{~m}$; and iii) $1.6 \mathrm{~m}$ to $2.1 \mathrm{~m}$;

- three positions across the canopy: i) left-hand side (relative to travel direction); ii) inside (i.e., leaves whose insertion was at less than $75 \mathrm{~mm}$ from the row); iii) right-hand side.

Each sample leaf was stored in a Petri dish. This meant 96 leaves in each of Tests 1-2, and 144 in each of Tests 3 to 5 .

All remaining leaves in each sample vine were then counted, and one leaf every five (Tests 1-2) or every ten (Tests 3-5) was taken and classified into the above defined sampling locations for the assessment of the leaf area index ( $L A I)$. Finally, bunches were counted, and eight of them taken for deposit assessment and placed in plastic bags.

The day after each experiment, spray deposits were assessed with the procedure described by Pergher (2000). Briefly, each sample was washed using $100 \mathrm{~mL}$ deionised water (leaves) or $200 \mathrm{~mL}$ (paper samples and bunches). Optical absorbance at $425 \mathrm{~nm}$ wavelength was assessed with a spectrophotometer (UV-VIS Lambda 5, Perkin-Elmer), and spray deposits $(d$, in $\mu \mathrm{L})$ were calculated as:

$d=10^{3} \frac{w A}{A_{m}}$

where $w$, in $\mathrm{mL}$, is the volume of water used to remove the tracer; $A$ is the absorbance of the washing solution; $A_{m}$ is the absorbance of the applied spray mixture.

Deposits were then expressed in $\mu \mathrm{L} / \mathrm{cm}^{2}$ leaf area (i.e., the total area of both leaf sides), $\mu \mathrm{L} / \mathrm{cm}^{2}$ ground area (paper samples), or $\mu \mathrm{L} / \mathrm{g}$ fresh weight (bunches). Background deposits from untreated leaves were always lower than $0.1 \%$ of the mean deposit on treated leaves, and no correction was applied to account for this.

The area of each sample leaf was measured with a photometric area-integrating meter (Model LI-3100C, LI-COR Inc.). The same was done with the leaves taken for leaf area assessment in each sample vine. The leaf area $\left(S_{i j}\right)$ in each of the sampling locations on the canopy, deriving from the combination of height range $(i)$ and position $(j)$, was calculated. Then, the $L A I$ and the leaf layer

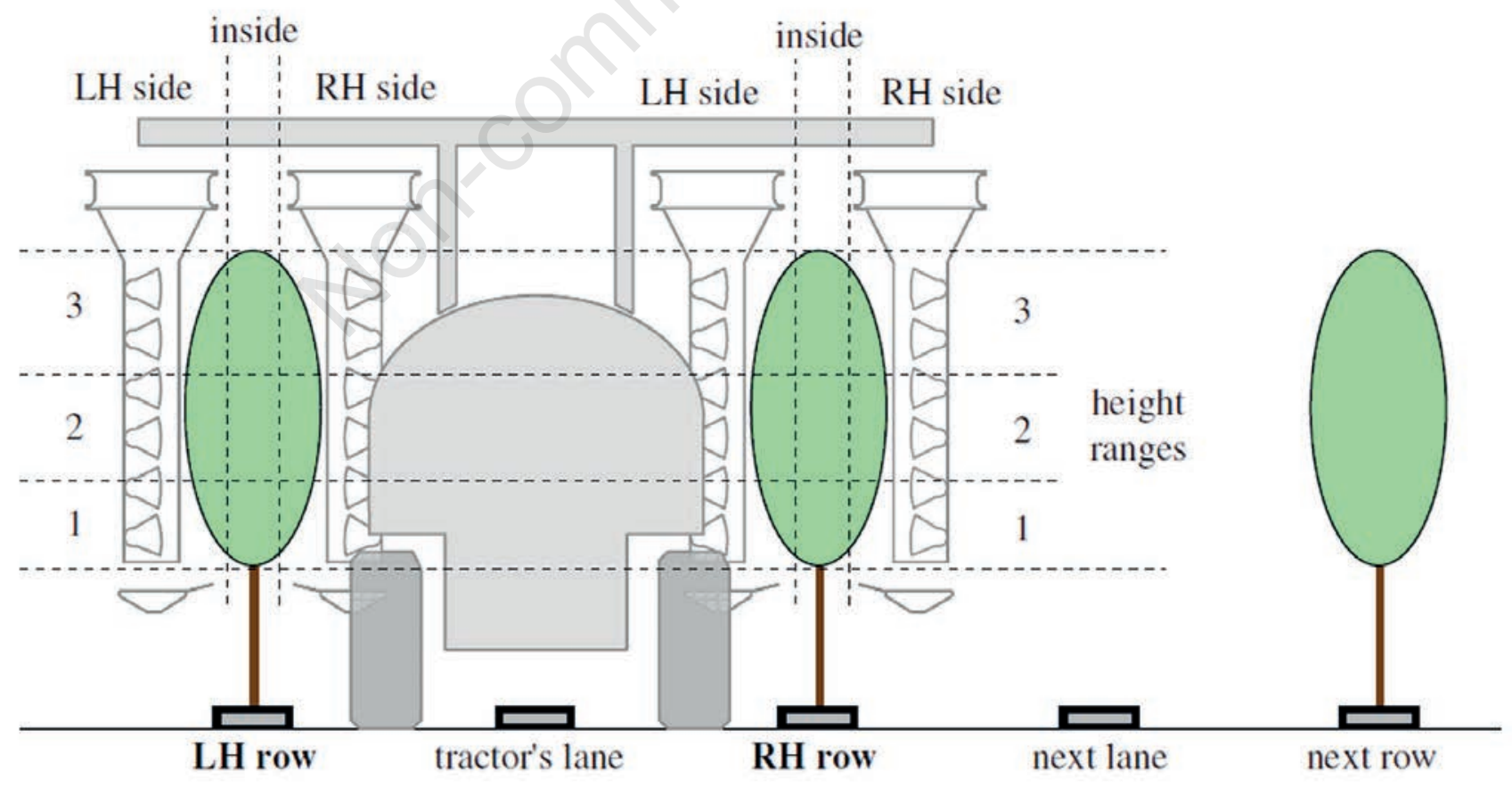

collectors for ground deposit assessment

Figure 3. The layout of sampling locations. 
index $(L L I)$ were calculated as:

$L A I=\frac{\sum_{i j} S_{i j}}{x b}$

$L L I=\frac{\sum_{j} S_{i j}}{x \Delta h_{i}}$

where $S_{i j}$, in $\mathrm{m}^{2}$, is the leaf area in location $(i, j)$; while $x, b$, and $\Delta h_{i}$, in $\mathrm{m}$, are the distance between the vines on the row, the row spacing, and the height range ( $i$ ) in the canopy, respectively.

The $L L I$ was defined by Pergher and Petris (2007) as the ratio of foliar area to the canopy cross-section in row direction, and proposed as an index of the number of leaf layers at a given height range in the canopy, or in the whole canopy.

Finally, the mean weighed foliar deposit $\left(d_{f w}\right.$, in $\left.\mu \mathrm{L} / \mathrm{cm}^{2}\right)$ and total deposition on the leaves $\left(D_{F}, \%\right)$, ground $\left(D_{G}, \%\right)$ and bunches $\left(D_{B}, \%\right)$ were determined for each sample vine with the equations:

$d_{f w}=\frac{\sum_{i j} d_{f(i j)} S_{i j}}{\sum S_{i j}}$

$D_{F}=2 \cdot 10^{4} d_{f w} \frac{L A I}{V}$

$D_{G}=10^{4} \frac{d_{g}}{V}$

$D_{B}=\frac{d_{b}}{V} w_{b}$

where $d_{f(i j)}$, in $\mu \mathrm{L} / \mathrm{cm}^{2}$, is the mean foliar deposit at canopy location (ij); $S_{i j}$, in $\mathrm{m}^{2}$, is the leaf area at the same location; $d_{g}$, in $\mu \mathrm{L} / \mathrm{cm}^{2}$, is the mean ground deposit; $d_{b}$, in $\mu \mathrm{L} / \mathrm{g}$, is the mean bunch deposit; $w_{b}$, in $\mathrm{g} / \mathrm{m}^{2}$, is the total bunch weight of the vine per unit ground area; and $V$, in $\mathrm{L} /$ ha, is the spray application volume; $x, b$ and $L A I$ are defined as above. For the purpose of mass balance assessment, ground losses under next lane and next row in the left side of the sprayer (Figure 4) were assumed as symmetrically distributed.
The recovery rate $(R)$ was assessed based on the amount of liquid recovered during the central pass in each test, and expressed in $\%$ of the application volume. The tracer concentration in the recovered liquid was also measured, and the evaporation loss $(E, \%$ of the volume applied) was calculated as:

$E=R\left(\frac{c_{R}}{c_{S}}-1\right)$

where $R$, in $\%$, is the recovery rate; $c_{R}$ is the tracer concentration in the recovered liquid; and $c_{M}$ is the tracer concentration in the spray mixture.

Analysis of variance of the mean foliar deposits in each sampling location was applied to Tests 3 to 5, assuming each as an independent, randomised complete blocks experiment, with four (Test 3) or three replicates (Tests 4 and 5), and three sources of

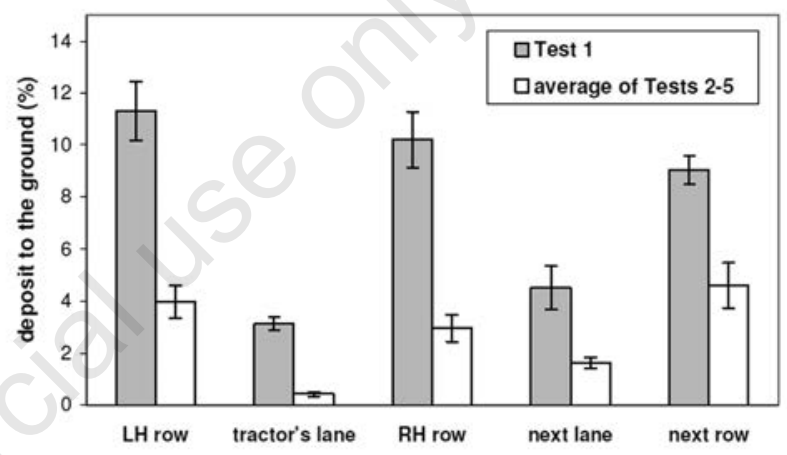

Figure 4. Ground deposits (\% of applied volume). Test $1 v s$ average of Tests 2-5. Means \pm standard error $(n=4)$.

Table 2. Canopy parameters.

\begin{tabular}{lccccc} 
Test & 1 & 2 & 3 & 4 & 5 \\
$\begin{array}{l}\text { Canopy height: } \\
\quad \text { minimum, m }\end{array}$ & 0.7 & 0.6 & 0.7 & 0.7 & 0.7 \\
$\quad$ maximum, m & 1.3 & 1.6 & 2.1 & 2.1 & 2.1 \\
$\quad$ range, m & 0.6 & 1.0 & 1.4 & 1.4 & 1.4 \\
Leaf area index (LAI) & 0.154 & 0.748 & 1.333 & 1.594 & 1.603 \\
\hline Leaf layer index (LLI) & 0.694 & 1.795 & 2.285 & 2.732 & 2.747 \\
Bunch weight, g/vine & & & 430 & 1970 & 1897 \\
\hline Bunch weight, g/m² & & & 224 & 1026 & 988 \\
Bunch weight, g/bunch & & & 23.9 & 76.4 & 72.9 \\
\hline
\end{tabular}

Table 3. Foliar weighed deposit $\left(d_{f w}\right)$, coefficient of variation of deposits on individual sample leaves (C.V.) and deposit on bunches $\left(d_{b}\right)$.

\begin{tabular}{|c|c|c|c|c|c|}
\hline \multirow[t]{2}{*}{ Test } & \multicolumn{2}{|c|}{$d_{f w}, \mu \mathrm{L} / \mathrm{cm}^{2}$} & \multirow[t]{2}{*}{ C.V., $\%$} & \multicolumn{2}{|c|}{$d_{b}, \mu \mathrm{L} / \mathrm{g}$} \\
\hline & Mean & Standard deviation & & Mean & Standard deviation \\
\hline 1 & 0.727 & 0.088 & 33.4 & & \\
\hline 2 & 0.652 & 0.070 & 47.2 & & \\
\hline 3 & 0.697 & 0.126 & 50.0 & 3.02 & 0.923 \\
\hline 4 & 0.709 & 0.083 & 42.5 & 1.20 & 0.248 \\
\hline 5 & 0.703 & 0.078 & 43.4 & 1.03 & 0.218 \\
\hline
\end{tabular}


variation: Height in the canopy (top, middle and bottom), Row ( $\mathrm{LH}$ and $\mathrm{RH}$ ) and Depth in the canopy (LH side, inside and $\mathrm{RH}$ side). Student-Newman-Keuls test was applied for mean comparison. The whole analysis was performed using the statistical package CoStat version 6.400 (Copyright 1998-2008, CoHort Software, Monterey, CA, 93940, USA).

\section{Results}

The $L A I$ of the vineyard increased from $0.15 \pm 0.02$ (mean \pm standard deviation; Test 1; Table 2) to $1.60 \pm 0.25$ (Test 5), i.e. more than ten times between $\mathrm{BBCH} 15$ and $\mathrm{BBCH} 77$, owing to an increase by 2.3 times in the canopy height range (from $0.6 \mathrm{~m}$ to 1.4 $\mathrm{m}$, respectively), and by nearly four times in the $L L I$ (from $0.69 \pm$ 0.11 to $2.75 \pm 0.43$, respectively).

The mean weighed foliar deposits (Table 3 ) were very similar across all growth stages, with a maximum in Test $1\left(0.727 \mu \mathrm{L} / \mathrm{cm}^{2}\right.$; i.e., $4 \%$ more than the average of all tests), and a minimum in Test $2\left(0.652 \mu \mathrm{L} / \mathrm{cm}^{2} ; 6 \%\right.$ less $)$. Test 4 and Test 5 , performed at the same growth stage, $\mathrm{BBCH} 77$, with hollow-cone Abbà nozzles and air-injection Albuz AVI nozzles, respectively, resulted in nearly the same mean deposit $\left(0.709\right.$ vs $\left.0.703 \mu \mathrm{L} / \mathrm{cm}^{2}\right)$.

Variability of foliar deposits, as expressed by the coefficients of variation (C.V.) between individual sample leaves, ranged from a minimum $33.4 \%$ in Test 1 to a maximum $50.0 \%$ in Test 3 (Table 3 ). In Test 1 , variability was probably limited by the low leaf area density ( $L L I$ was 0.69 ; Table 2 ) at that growth stage.

Tests 3 to 5 were further analysed by comparing foliar deposits at the different sampling locations across the canopy. Analysis of variance (Table 4) showed that all sources of variation (height and depth in the canopy, and row) had significant effects on foliar deposits.

Differences between the inside and outside of canopy were observed in all Tests, although statistically significant only in Tests 3 and 5 (Table 5). The largest variation was observed in Test 3 ( $-22 \%$, inside of canopy versus average of LH and RH in the outside).

Significant differences across the height ranges were observed in Test 3, with a maximum deposit at the top height, and Test 4, with a minimum at the middle height range (Table 5). Both differences were associated with opposite variations in the leaf area: in fact, in Test 3, the $L L I$ was lowest at the top of canopy (1.47, height 3 , vs 2.74, mean of heights 1-2), while highest in Test 4 at the central height (3.35, height 2 , vs 2.45, mean of heights 1 and 3 ). Noticeably, no significant differences were found in Test 5, performed with air-injection nozzles, so that the observed overall variability must owe, in this case, to differences between individual leaves rather than between sampling locations.

Table 4. Degrees of freedom (df) and probability levels $(\mathrm{P})$ in the analysis of variance of foliar deposits.

\begin{tabular}{|c|c|c|c|c|c|c|c|c|c|}
\hline Sources of variation & df & $\begin{array}{c}\text { Test } 3 \\
\text { P }\end{array}$ & & & $\begin{array}{c}\text { Test } 4 \\
\text { P }\end{array}$ & & df & $\begin{array}{c}\text { Test } 5 \\
\text { P }\end{array}$ & \\
\hline Blocks & 3 & 0.0023 & $* *$ & 2 & 0.2875 & & 2 & 0.3797 & \\
\hline $\begin{array}{l}\text { Main effects } \\
\text { Height } \\
\text { Depth } \\
\text { Row }\end{array}$ & $\begin{array}{l}2 \\
2 \\
1\end{array}$ & $\begin{array}{l}0.0000 \\
0.0044 \\
0.2160\end{array}$ & $\begin{array}{l}* * \\
* *\end{array}$ & $\begin{array}{l}2 \\
2 \\
1\end{array}$ & $\begin{array}{l}0.0101 \\
0.5816 \\
0.0828\end{array}$ & $*$ & $\begin{array}{l}2 \\
2 \\
1\end{array}$ & $\begin{array}{l}0.6667 \\
0.0478 \\
0.4688\end{array}$ & $*$ \\
\hline $\begin{array}{l}\text { Interaction } \\
\text { Height x Depth } \\
\text { Height x Row } \\
\text { Depth x Row } \\
\text { Height x Depth x Row }\end{array}$ & $\begin{array}{l}4 \\
2 \\
2 \\
4\end{array}$ & $\begin{array}{l}0.0903 \\
0.0107 \\
0.2824 \\
0.4040\end{array}$ & $*$ & $\begin{array}{l}4 \\
2 \\
2 \\
4\end{array}$ & $\begin{array}{l}0.5961 \\
0.0171 \\
0.8988 \\
0.4470\end{array}$ & $*$ & $\begin{array}{l}4 \\
2 \\
2 \\
4\end{array}$ & $\begin{array}{l}0.0402 \\
0.2638 \\
0.9014 \\
0.2718 \\
\end{array}$ & $*$ \\
\hline
\end{tabular}

Significant effects are shown at $* \mathrm{P}<0.05$ or $* * \mathrm{P}<0.01$.

Table 5. Effects of the sources of variation on the mean foliar deposits $\left(d f\right.$, in $\left.\mu L / \mathrm{cm}^{2}\right)$. The $L L I$ at each canopy height is reported for comparison.

\begin{tabular}{|c|c|c|c|c|c|c|c|c|c|c|}
\hline Test & Height in the canopy & $\begin{array}{l}\text { Dep } \\
\mathrm{LH} \text { side } \\
d_{f,} \mathrm{\mu L} / \mathrm{cm}^{2}\end{array}$ & $\begin{array}{l}\text { h in the car } \\
\text { Inside } \\
d_{f, \mu \mathrm{L} / \mathrm{cm}^{2}}\end{array}$ & $\begin{array}{l}\text { Py } \\
\text { RH side } \\
d_{f}, \mathrm{HL} / \mathrm{cm}^{2}\end{array}$ & $\begin{array}{c}\text { LH row } \\
d_{f}, 11 \mathrm{~L} / \mathrm{cm}^{2}\end{array}$ & $L L I$ & $\begin{array}{c}\text { RH row } \\
d_{f, j \mathrm{H} / \mathrm{cm}^{2}}\end{array}$ & $L L$ & $d_{f}, \mu \mathrm{L} / \mathrm{cm}^{2}$ & $L L I$ \\
\hline 3 & $\begin{array}{l}\text { 1) bottom }(0.7-1.15 \mathrm{~m}) \\
\text { 2) middle }(1.15-1.6 \mathrm{~m}) \\
\text { 3) top }(1.6-2.1 \mathrm{~m}) \\
\text { Mean* }\end{array}$ & $\begin{array}{l}0.812 \\
0.711 \\
1.100 \\
0.875^{\mathrm{a}}\end{array}$ & $\begin{array}{l}0.725 \\
0.412 \\
0.805 \\
0.647^{\mathrm{b}}\end{array}$ & $\begin{array}{c}0.601 \\
0.740 \\
0.986 \\
0.775^{\mathrm{ab}}\end{array}$ & $\begin{array}{l}0.564 \\
0.619 \\
1.014 \\
0.732\end{array}$ & $\begin{array}{c}3.69 \\
2.83 \\
1.32 \\
0.799\end{array}$ & $\begin{array}{l}0.862 \\
0.623 \\
0.913 \\
0.766\end{array}$ & $\begin{array}{l}2.03 \\
2.40 \\
1.62\end{array}$ & $\begin{array}{l}0.713^{\mathrm{a}} \\
0.621^{\mathrm{b}} \\
0.963^{\mathrm{a}}\end{array}$ & $\begin{array}{l}2.86 \\
2.62 \\
1.47\end{array}$ \\
\hline 4 & $\begin{array}{l}\text { 1) bottom }(0.7-1.15 \mathrm{~m}) \\
\text { 2) middle }(1.15-1.6 \mathrm{~m}) \\
\text { 3) top }(1.6-2.1 \mathrm{~m}) \\
\text { Mean* }\end{array}$ & $\begin{array}{l}0.814 \\
0.508 \\
0.815 \\
0.712^{\mathrm{a}}\end{array}$ & $\begin{array}{l}0.709 \\
0.523 \\
0.743 \\
0.658^{a}\end{array}$ & $\begin{array}{l}0.769 \\
0.680 \\
0.732 \\
0.727^{a}\end{array}$ & $\begin{array}{l}0.873 \\
0.500 \\
0.875 \\
0.749\end{array}$ & $\begin{array}{c}2.10 \\
3.34 \\
2.58 \\
0.649\end{array}$ & $\begin{array}{l}0.655 \\
0.640 \\
0.651 \\
0.699\end{array}$ & $\begin{array}{l}3.09 \\
3.35 \\
2.02\end{array}$ & $\begin{array}{l}0.764^{\mathrm{a}} \\
0.570^{\mathrm{b}} \\
0.763^{\mathrm{a}}\end{array}$ & $\begin{array}{l}2.60 \\
3.35 \\
2.30\end{array}$ \\
\hline 5 & $\begin{array}{l}\text { 1) bottom }(0.7-1.15 \mathrm{~m}) \\
\text { 2) middle }(1.15-1.6 \mathrm{~m}) \\
\text { 3) top }(1.6-2.1 \mathrm{~m}) \\
\text { Mean* }\end{array}$ & $\begin{array}{l}0.981 \\
0.744 \\
0.720 \\
0.815^{\mathrm{a}}\end{array}$ & $\begin{array}{l}0.671 \\
0.650 \\
0.659 \\
0.660^{b}\end{array}$ & $\begin{array}{c}0.572 \\
0.819 \\
0.691 \\
0.694^{\mathrm{ab}}\end{array}$ & $\begin{array}{l}0.705 \\
0.763 \\
0.758 \\
0.742\end{array}$ & $\begin{array}{c}2.20 \\
3.23 \\
1.99 \\
0.704\end{array}$ & $\begin{array}{l}0.778 \\
0.713 \\
0.622 \\
0.723\end{array}$ & $\begin{array}{l}1.66 \\
4.35 \\
3.11\end{array}$ & $\begin{array}{l}0.741^{\mathrm{a}} \\
0.738^{\mathrm{a}} \\
0.690^{\mathrm{a}}\end{array}$ & $\begin{array}{l}1.93 \\
3.79 \\
2.55\end{array}$ \\
\hline
\end{tabular}

*In each Test, the means denoted by the same letter are not statistically different at $\mathrm{P}<0.05$ (Student-Newman-Keuls test). 
No significant differences were found either between the LH and $\mathrm{RH}$ rows (i.e., sprayed with the corresponding units of the tunnel), or between the LH and RH sides of the canopy in each row. However, analysis of variance (Table 4) signalled that the interaction Height $\mathrm{x}$ Row was significant for both Test 3 and Test 4 . This was consistent with the different distributions of deposits over the height ranges observed at the $\mathrm{LH}$ and $\mathrm{RH}$ rows, respectively (Table 5): more particularly, differences between the $\mathrm{LH}$ and $\mathrm{RH}$ rows were observed at the bottom of canopy in Test 3, and at height ranges 1 (bottom) and 3 (top) in Test 4 . Even such effects were, however, mostly associated with variations in the $L L I$ in the opposite directions.

The mean spray deposits on bunches decreased from Test 3 (3.02 $\mu \mathrm{L} / \mathrm{g}$ fresh weight; Table 3$)$ to Tests $4-5(1.20 \mu \mathrm{L} / \mathrm{g}$ and 1.03 $\mu \mathrm{L} / \mathrm{g}$, respectively). This was consistent with the increase in mean bunch weight (from $23.9 \mathrm{~g} / \mathrm{bunch}$ in Test 3 to $74.7 \mathrm{~g} / \mathrm{bunch}$, average of Tests 4-5; Table 2), and the consequent reduction in the area/weight ratio. The difference in bunch deposits between Test 4 (Abbà nozzles) and Test 5 (Albuz AVI nozzles) was not statistically significant (at $\mathrm{P}=0.05$; Student-Newman-Keuls test).

Total foliar deposition (Table 6) ranged from 14.8\% (Test 1 ) to $51.2 \%$ (Test 4 ) of the spray volume applied. Deposition on bunches was not measured in Test 1-2; in the following tests, it accounted for just $1.9 \%$ (Test 3 ) to $2.7-2.4 \%$ (Tests 4 and 5 , respectively). Such difference was mainly owing to the increase in the bunch weight (430 g/vine vs 1970-1897 g/vine, respectively), since the mean spray deposition per unit bunch weight $(\mu \mathrm{L} / \mathrm{g})$ actually decreased from Test 3 to Tests 4-5, as above reported.

Deposition to the ground, including the fraction that drifted from the two adjacent rows on either side, was much higher in Test $1(8.1 \%$ of applied volume, Table 6$)$ than in all other tests $(1.9 \%$, Test 5 , to $2.6 \%$, Test 4$)$. The relatively large loss in Test 1 was certainly related to the wider tunnel opening $(800 \mathrm{~mm})$. In all Tests, most of deposition was found below the rows, while the minimum was always in the middle of the tractor's lane (Figure 4).

The recovery rate (Table 6) ranged from a maximum $67.2 \%$ (Test $1, \mathrm{BBCH} 15$ ) to a minimum $31.0 \%$ (Test 4, BBCH 77), with a decrease typically recorded for tunnel sprayers, following canopy development and the consequent increase in LAI. However, Albuz AVI air-injection nozzles (Test 5) gave a substantially higher recovery rate (36.1) as compared with Abbà hollow-cone nozzles (Test 4$)$ at the same growth stage and with very similar LAI (1.60 vs 1.59 , respectively, Table 1). Tracer concentration in the recovered liquid increased by $3.0 \%-6.5 \%$ in the Tests performed with hollow-cone nozzles, while only by $0.2 \%$ in Test 5 (air-injection nozzles); as a consequence, spray losses owing to partial evaporation of the recovered liquid ranged from $2.0 \%$ to $3.5 \%$ in Tests 1 to 4 , while only $0.1 \%$ in Test 5 (Table 6).

Unaccounted-for spray volume, resulting from the difference between the total spray volume and the sum of deposits, losses and recovery, was $6.5 \%$ to $10.6 \%$. Such difference was depending on several factors, including: deposition to the vineyard structure (such as posts and wires), deposition on parts of the vines other than leaves (i.e. trunks, stems, petioles, tendrils), spray losses owing to drift towards the outside of experimental plots, and deposition on the sprayer itself, particularly in the inside of the tunnel. It was not within the extent and scope of the present study to analyse such deposits and spray losses. Anyway, the difference in unaccounted-for spray volume between Tests 4 and 5 (10.6\% vs $8.8 \%$, respectively) may have reflected a difference in airborne drift between the hollow-cone and the air-injection nozzles.

\section{Discussion}

The $L L I$ was by $7 \%$ to $60 \%$ higher than previously recorded in VSP guyot and spur-cordon vineyards (Pergher and Petris, 2008a; Pergher et al., 2013). Moreover, and despite careful canopy management, at least since BBCH 73 (Test 3; $L L I=2.28$; Table 2) the $L L I$ was exceeding the levels recommended for efficient light interception and easy spray penetration (1.5 to 2 leaf layers, according to Balsari and Scienza, 2003); thus, the vineyard could be considered as having a relatively dense canopy.

The differences in mean deposition across the growth stages, and particularly the relative decrease at $\mathrm{BBCH} 57$ (inflorescences

Table 6. Spray deposition and losses (\% of volume applied).

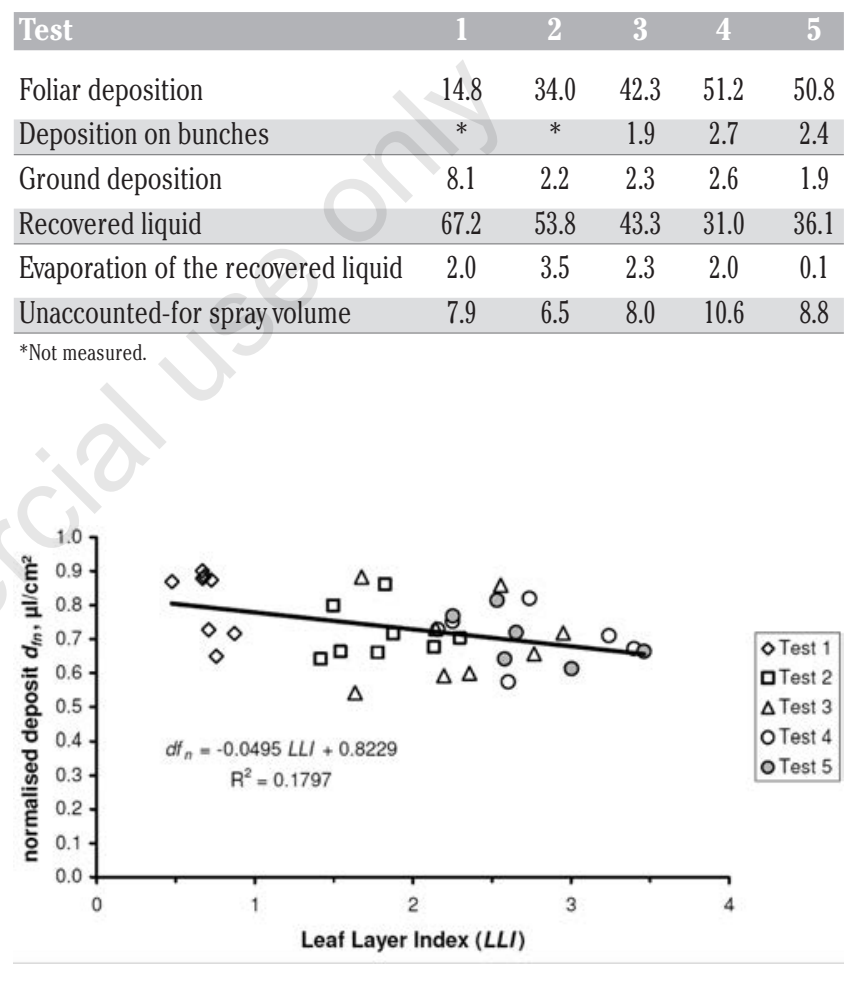

Figure 5. Normalised foliar deposits vs leaf layer index.

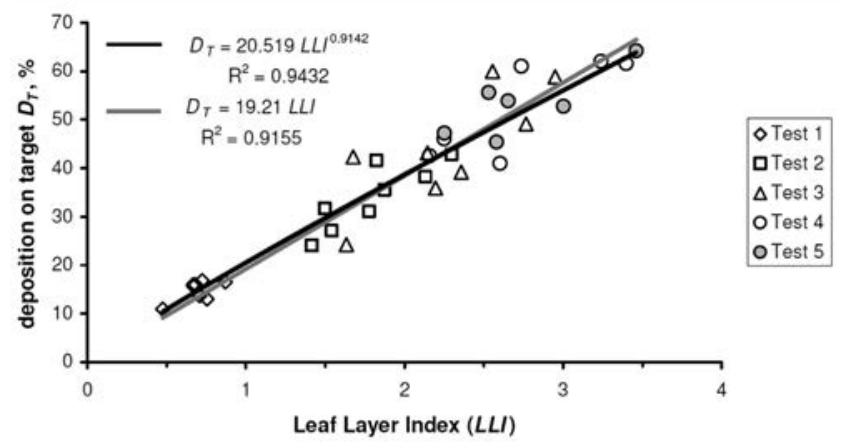

Figure 6. Target deposition (leaves and bunches, \% of volume applied) $v s$ leaf layer index. 
fully developed, Test 2), might be related to inadequate choice of the spray volumes, following the simple and common method of adjusting the number of open nozzles by visual assessment of canopy size. An alternative would have been to use spray volumes proportional to the leaf wall area (LWA) of the vineyard at each growth stage, given by (Pergher and Petris, 2008b; Walklate et al., 2011):

$$
L W A=10^{4} \frac{h}{b}
$$

where $L W A, \mathrm{~m}^{2} / \mathrm{ha}$, is the one-sided leaf wall area; $h$, in $\mathrm{m}$, is the height range of the canopy; and $b$, in $\mathrm{m}$, is the row spacing.

In fact, the ratio of spray application volume to LWA was 0.075 $\mathrm{L} / \mathrm{m}^{2}$ in Tests $3-5$, while only $0.068-0.069 \mathrm{~L} / \mathrm{m}^{2}$ in Tests $1-2$, respectively. Therefore, application of the LWA method would have suggested to increase the spray volumes by $12 \%$ (Test 1 ) or $10 \%$ (Test 2). It may be assumed that foliar deposition would then have increased by nearly the same extent, so as to result slightly higher at BBCH 57 (Test 2) than at the later growth stages (Tests $3-5)$, while substantially higher $(+15 \%)$ at BBCH 15 (Test 1$)$. Such consequence, possibly owing to the very low number of leaf layers in Test $1(L L I=0.694$, Table 2; see also Figure 5 and related discussion) would not be undesirable, since it could ensure better pest control at the earlier growth stages, which are generally considered, under this respect, as the most critical in viticulture.

The sum of total foliar and bunch deposition, i.e. the volume fraction of sprayer output retained as target deposit (Pergher and Petris, 2008b; Walklate et al., 2011), or crop interception (Jensen and Olesen, 2014), may be used as an index of the efficiency of spray deposition. Total deposition on target $\left(D_{T}\right)$ increased nearly proportionally with the $L L I$, following the development of the canopy since BBCH 15 to BBCH 77 (Figure 6). The regression:

$D_{T}=20.519 L L I^{0.9142}$

was highly significant, and explained $94.3 \%$ of the observed variability (coefficient of determination, $\mathrm{R}^{2}=0.9431$ ). It was also very close to a relationship of direct proportionality. In fact, the linear regression (gray line in Figure 6):

$D_{T}=19.21 L L I$

would explain $91.5 \%$ of the observed variability $\left(\mathrm{R}^{2}=0.9155\right)$. Considering foliar deposition alone $\left(D_{F}\right)$, without bunch deposition, a similar regression was calculated $\left(\mathrm{R}^{2}=0.9411\right)$ :

$D_{F}=20.37 L L I^{0.8896}$.

However, all these regressions may be considered biased by the fact that total foliar deposition and $L L I$ were, in each sample vine, directly proportional to the total leaf area and, therefore, necessarily correlated to each other. For this reason, it may be interesting to examine the relationship between the $L L I$ and the mean deposits per unit leaf area $\left(\mu \mathrm{L} / \mathrm{cm}^{2}\right)$ as well, as shown in Figure 5. To account for the differences in the spray volume rates $\mathrm{L} / \mathrm{ha}$ ), the same volume per unit LWA, $0.075 \mathrm{~L} / \mathrm{m}^{2}$, was assumed for all Tests; consequently, deposits from Tests 1 and 2 were normalised, i.e. increased proportionally to the increase in the (assumed) volume rate. The regression (Figure 5) was statistically significant (at $\mathrm{P}<0.01$ ), showing an average decrease in deposition by nearly $19 \%$ for a variation in the $L L I$ from 0.5 to 3.5 . However, the low determination coefficient $\left(\mathrm{R}^{2}=0.1797\right)$ indicated that most of deposit variability was owing to other factors.

On the other hand, local variations in deposits were indeed observed, particularly in Tests 3 and 4, associated with opposite variations in $L L I$ at the same location on the canopy (Table 5). However, this was not consistently recorded at all canopy locations and in all Tests. Considering the limited influence of $L L I$ on foliar deposits, described by the regression in Figure 5, the effect might result statistically significant only in the presence of relatively large changes in $L L I$ between adjacent locations, possibly causing local deflections in the spray fluxes towards canopy locations with lower foliar density. This might explain why it could be easier observed locally (Table 5; particularly in Tests 3 and 4), than on the whole sample vines (Figure 5). Anyway this suggests that, in order to minimise deposit variability, good canopy management aimed at reducing leaf area density variability might be nearly as important as careful adjustment of nozzle and air jet directions in the sprayer.

The existence of a linear proportionality between target deposit and $L L I$ is a critical assumption in the LWA model. In its original definition (Koch and Weisser, 2002), the model states that the pesticide dose rate (and, for a fixed pesticide concentration, the spray volume rate as well) should be adjusted proportionally to the crop LWA in order to obtain a given, constant deposit per unit target, and does not consider the $L L I$ or any other index of leaf area density. In fact, the model assumes that any increase in $L L I$ would increase deposition efficiency (i.e., the volume fraction of sprayer output retained as target deposit) by the same extent, so as to result in constant average deposits per unit leaf area. On the other hand, if the assumption of a linear relationship between deposition efficiency and $L L I$ cannot be proven, then some correction factor of pesticide rates and volume rates would be needed to account for LLI variations (Walklate et al., 2011). Pergher and Petris (2008b) analysed 42 deposition tests, performed during 1993 to 2005, and found that the LWA method could be considered sufficiently accurate in a wide range of vineyards with $L L I<4$. The results from the present field tests seem to confirm those previous findings.

The spray losses to the ground recorded in the present study were comparable to those $(1.6 \%$ to $4.8 \%)$ reported from other airassisted tunnel sprayers (Ade et al., 2005, 2007), while lower than those $(6 \%$ to $23 \%)$ from tunnels without fans (Siegfried and Raisigl, 1991; Balsari and Tamagnone, 1996; Viret et al., 2003). This shows another advantage of air-assistance in tunnel sprayers.

Tracer concentration in the recycled liquid increased by $3.0 \%$ $6.5 \%$ in the tests performed with hollow-cone nozzles. Several studies (Pergher et al., 2001; Ade et al., 2007; Tamagnone et al., 2013) have analysed pesticide or tracer concentration in the tank of recycling sprayers, and reported increases of $2 \%$ to $6 \%$ over the original concentration. However, such assessments may be ambiguous, since tank concentration depends on the proportion of recycled to unrecycled (original) spray mixture, and will continuously increase while the same volume of liquid is recycled over and over. A side experiment was performed the day after Test 5, spraying 3.7 ha in a nearby vineyard with a mixture containing $4.55 \mathrm{~g} / \mathrm{L}$ of a pesticide (Penncozeb 20, Cerexagri) and $0.54 \mathrm{~g} / \mathrm{L}$ of Tartrazine. Sprayer settings were the same as for Test 4 . The initial and final volume in the tank was $1300 \mathrm{~L}$ and 561 , respectively; and average recovery rate was $24.5 \%$. At the end of application, tracer concentration in the tank had increased by $13.3 \%$. This suggests that the problem should be further analysed, since it might lead to undesirable increase in pesticide dose applied, particularly while spraying the last fraction of the tank volume, and/or to difficult disposal of the residual spray mixture. 
Foliar spray deposition from air-injection nozzles was not noticeably different from that of hollow-cone nozzles. This confirms some previous studies (Jamar et al., 2010), while contrasting with others (Carra, 2017). The main advantage of air-injection nozzles was the substantial increase in spray recovery rate $(36.1 \% \mathrm{vs}$ $31.0 \%$ from hollow-cone nozzles, Test 5 vs Test 4). Additionally, the very low concentration rise $(0.2 \%)$, if confirmed by further tests, possibly under different weather conditions, might be a solution to avoid any problems related to excessive tank concentration or leftovers.

\section{Conclusions}

Tunnel, recycling sprayers for vineyards are increasingly replacing conventional, broadcast sprayers because of their ability of reducing soil contamination and airborne drift, while recovering and recycling most of the spray volume (30\% to $67 \%$ in the present tests) so as to make efficient pest control possible even at reduced pesticide dose rates. The environmental and economic importance of reduced pesticide consumption can be hardly overstressed in such rainy climates as in North-Eastern Italy, where 15 to 20 applications per year are common practice, and the cost of pesticides may range from 40 to $80 € /$ ha per application.

However, several issues remain open, including the correct calibration of volume application rates following canopy development during the season. The simple and common method of adjusting the number of open nozzles by visual assessment of canopy size, used in the present tests, resulted in relatively limited variations in foliar deposits per unit leaf area, with a clear decrease, however, at BBCH 57 (inflorescences fully developed, Test 2; 8\% less than in Test 4). This might have probably been avoided by using spray volumes proportional to the LWA. In fact, the relationship of nearly linear proportionality found between total target deposition and the $L L I$ seemed to confirm the main postulate of the LWA theory (Pergher and Petris, 2008b). Further research is needed, anyway, to extend these findings to vineyards with different canopy size, leaf area density and training systems, and more particularly to canopies with $L L I>3$ and free shoots, such as in the GDC and free cordon training systems (Intrieri, 2013). The tests, in fact, also pointed to the importance of a good canopy management to keep the foliage width as narrow as possible to avoid drift losses, and leaf density sufficiently uniformly distributed so as to reduce deposit variability owing to local deflections in the spray and air fluxes.

One undesired effect observed in this sprayer was the increase in tracer concentration in the recycled liquid, which ranged from $3.0 \%$ to $6.5 \%$ of the original concentration in the tests performed with hollow-cone nozzles. This may potentially lead to an excessive increase in the pesticide dose applied, particularly while spraying the last fraction of the tank volume. A solution might be the use of air-injection nozzles that resulted in a very limited concentration rise $(0.2 \%)$ in Test 5 . An additional advantage of airinjection nozzles was an increase in spray recovery rate $(36.1 \% \mathrm{vs}$ $31.0 \%$ from hollow-cone nozzles, Test 5 vs Test 4).

\section{References}

Ade G., Molari G., Rondelli V. 2005. Vineyard evaluation of a recycling tunnel sprayer. Trans. ASAE 48:2105-12.

Ade G., Molari G., Rondelli V. 2007. Recycling tunnel sprayer for pesticide dose adjustment to the crop environment. Trans.
ASABE 50:409-13.

Ambrogetti A.O., Uliarte E.M., Montoya M.A., Haist W., del Monte R.F. 2016. Evaluación de un panel para recuperación de deriva en aplicaciones fitosanitarias en viñedos [Evaluation of a drift recovery panel for phytosanitary treatments in vineyards]. Rev. FCA UNCuyo 47:83-95.

Baldoin C., De Zanche C., Bondesan D. 2008. Field Testing of a Prototype Recycling Sprayer on Vineyard: Spray Distribution and Dispersion. Agricultural Engineering International: the CIGR Ejournal, Vol. X.

Balsari P., Scienza A. 2003. Forme di allevamento della vite e modalità di distribuzione dei fitofarmaci [Training systems of the vine and methods for pesticide application]. Bayer CropScience, Milano, Italy.

Balsari P., Tamagnone M. 1996. Prime valutazioni di una irroratrice a tunnel impiegata in viticoltura [First evaluation of a tunnel sprayer working in vineyards]. Proc. Giorn. Fitopatol. $1: 439-46$.

Baraldi G., Bovolenta S., Pezzi F., Rondelli V. 1993. Air-assisted tunnel sprayers for orchard and vineyard: first results. Proc. Symposium international sur les techniques d'application des produits phytosanitaires, 22-24 September 1993, Strasbourg, France, 1:265-72.

Bera B. 1985. Bemerkungen über den Bau und Anwendung der Tunnelspritzgeräte bei der Schädlingsbekämpfung im Obstbau [Notes on the construction and use of tunnel sprayers for controlling pests in orchards]. Erwerbsobstbau 27:60-2.

Carra M., Delpuech X., Codis S., Douzals J., Montegano P., Ruelle B., Savajols B., Ribeyrolles X., Vergès A. 2017. Spray deposits from a recycling tunnel sprayer in vineyard; effects of the forward speed and the nozzle type. Book of Abstracts, Suprofruit 2017, pages 33-34; 14th Workshop on Spray Application in Fruit Growing, May 10-12, Hasselt, Limburg, Belgium.

European Union. 2009. Directive 2009/128/CE on sustainable use of pesticides. Official Journal, L 309, 24/11/2009, pp 71-86.

Intrieri C. 2013. Research and innovation for full mechanization of Italian vineyards at Bologna University. Acta Hortic. 978:151-68.

Jamar L., Mostade O., Huyghebaert B., Pigeon O., Lateur M. 2010. Comparative performance of recycling tunnel and conventional sprayers using standard and drift-mitigating nozzles in dwarf apple orchards. Crop Prot. 29:561-6.

Jensen P.K., Olesen M.H. 2014. Spray mass balance in pesticide application: a review. Crop Prot. 61:23-31.

Koch H., Weisser P. 2002. Expression of dose rate with respect to orchard sprayer function. Adv. Appl. Biol. 66:353-8.

Lorenz D., Eichorn D., Bleiholder H., Klose R., Meier U., Weber E. 1994. Phänologische Entwicklungsstadien der Weinrebe (Vitis vinifera L. ssp. vinifera). Codierung und Beschreibung nach der erweiterten BBCH-Skala. Vitic. Enol. Sci. 49:66-70.

Molari G., Bentini L., Ade G. 2005. Design of a recycling tunnel sprayer using CFD simulations. Trans. ASAE 48:463-8.

Panneton B., Lacasse B., Piché M. 2005. Effect of Air-jet Configuration on Spray Coverage in Vineyards. Biosyst. Eng. 90:173-84.

Pergher G. 2000. Recovery Rate of Tracer Dyes Used for Deposit Assessment. 2000 ASAE Annual International Meeting, July 8-12, Milwaukee, Wisconsin, WI, USA.

Pergher G., Gubiani R., Dell'Antonia D., Cividino S.R.S., Lagazio C. 2013. Assessment of spray deposition and recycling rate in the vineyard from a new type of air-assisted tunnel sprayer. Crop Prot. 45:6-14.

Pergher G., Gubiani R., Rizzi C., Zucchiatti N. 2001. Verifica sperimentale di un'irroratrice a tunnel per vigneto [Experimental 
evaluation of a vineyard tunnel sprayer]. Proc. VII Convegno Nazionale di Ingegneria Agraria, 11-14 September, Vieste, Italy.

Pergher G., Petris R. 2007. Canopy structure and deposition efficiency of vineyard sprayers. J. Agr. Eng. 2:53-60.

Pergher G., Petris R. 2008a. The Effect of Air Flow Rate on Spray Deposition in a Guyot-trained Vineyard. Agricultural Engineering International. Manuscript ALNARP 08 010. Vol. X. May.

Pergher G., Petris R. 2008b. Pesticide Dose Adjustment in Vineyard Spraying and Potential for Dose Reduction. Agricultural Engineering International. Manuscript ALNARP 08 011. Vol. X. May.

Pergher G., Petris R. 2009. A novel, air-assisted tunnel sprayer for vineyards: optimization of operational parameters and first assessment in the field. J. Agr. Eng. 4:39-46.

Planas S., Solanelles F., Fillat A. 2002. Assessment of recycling tunnel sprayers in Mediterranean vineyards and apple orchards. Biosyst. Eng. 82:45-52.

Siegfried W., Holliger E. 1996. Application Technology in Fruit-
Growing and Viticulture. Report, Swiss Federal Research Station, Wädenswill, Switzerland.

Siegfried W., Raisigl U. 1991. Erste Erfahrungen mit dem JocoRecyclinggerät im Rebbau [First experiences with the Joco recycling sprayer in viticulture]. Schweizer. Zeitschr. Obst Weinbau 127:154-60.

Southcombe E.S.E., Miller P.C.H., Ganzelmeier H., Zande J.C. van de, Miralles A., Hewitt A.J. 1997. The international (BCPC) spray classification system including a drift potential factor. pp 371-380 in Proc. Brighton Crop Prot. Conf-Weeds, Nov. Brighton, UK.

Tamagnone M., Balsari P., Bozzer C. 2013. Performance evaluation of recycling sprayer in vineyard. Acta Hortic. 978:199-204.

Viret O., Siegfried W., Holliger E., Raisigl U. 2003. Comparison of spray deposits and efficacy against powdery mildew of aerial and ground-based spraying equipment in viticulture. Crop Prot. 22:1023-32.

Walklate P.J., Cross J.V., Pergher G. 2011. Support system for efficient dosage of orchard and vineyard spraying products. Comput. Electron. Agric. 75:355-62. 